Open Access

\title{
An examination of Vygotsky's socio-cultural theory in second language acquisition: the role of higher order thinking enhancing techniques and the EFL learners' use of private speech in the construction of reasoning
}

Sepideh Mirzaee and Parviz Maftoon ${ }^{*}$

* Correspondence: pmaftoon@gmail.com Department of English Language, Science and Research Branch, Islamic Azad University, Tehran, Iran

\begin{abstract}
The present study investigates the impact of higher order thinking enhancing techniques as two post-reading strategies on the EFL students' reasoning power as determined by their private speech production. Also, the relationship between the learners' private speech production and their reasoning power is also investigated. In so doing, the study utilizes a quasi-experimental design with 30 participants in each control and experimental groups. The results of the pretest administration indicate that the participants of the two groups are homogenous regarding their language proficiency level as determined by the Babel Test, and their reasoning power as determined by the Watson-Glaser Critical Thinking Appraisal (W-GCTA). The participants in the experimental group are instructed in a way to enhance their reasoning power based on 6 reading comprehension texts. WGCTA's two subtests of deduction and inference making which contain reasoning-gap tasks are utilized as the posttest. While the participants are engaged in carrying out such tasks, their private speech productions are recorded. Data analysis and transcription indicate that private speech which is categorized into 4 classes in this study has a positive and significant influence on the learners' reasoning power. Higher order thinking enhancing techniques are also found to have impact on the experimental group in enhancing their private speech production and subsequently improving their reasoning. The detailed results, discussion, and conclusions of the research are further presented.
\end{abstract}

Keywords: Logical reasoning, Private speech, Higher order thinking enhancing techniques, Reasoning-gap tasks, Quasi-experimental design, Watson-Glaser critical thinking appraisal

\section{Introduction}

The human's cognitive development, in general, and higher order abilities, in particular, have long been under debate. Studies on these issues started by carrying out a bulk of research over children and after that on adults. Gradually, linguists became among those who were interested in working on the relationship between human's

(C) The Author(s). 2016 Open Access This article is distributed under the terms of the Creative Commons Attribution 4.0 International License (http://creativecommons.org/licenses/by/4.0/), which permits unrestricted use, distribution, and reproduction in any medium, provided you give appropriate credit to the original author(s) and the source, provide a link to the Creative Commons license, and indicate if changes were made. 
cognitive development and language learning. When Vygotsky (1986) proposed sociocultural theory $(\mathrm{SCT})$, a new perspective was presented regarding the relationship between human beings' cognitive development and language learning. However, the most outstanding studies in this domain were limited to the child's cognitive development and less were related to adults'.

In fact, Vygotsky (1986) maintains that SCT is regarded as a theory of human cognitive development and higher mental functions. He states that the human cognitive development and higher mental functions initiate from social communications; and while people participate in social activities, they are involved in mental and communicative functions. As a matter of fact, SCT considers mental functioning as a mediated process in which there should be some artifacts in order to mediate between the human's psychological and social worlds.

Therefore, the present study compatible with SCT, in general, and private speech, as well as higher order thinking, in particular, aimed at analyzing the private speech use of participants in order to determine their power of logical reasoning while doing reasoning-gap tasks to see whether there are any significant differences between those who are treated using specific higher order thinking enhancing techniques in reading comprehension (RC) and those who are not.

Hereafter, to achieve the very primary goal, the present researchers hold that by studying the specific instances of learners' private speech in which it can be categorized into a variety of types, we are able to further understand the relationship among higher order thinking enhancing techniques, private speech, and learners' reasoning. In other words, this effort is meaningful since it helps us have a better understanding of the nature of private speech, and it entails the exploration of its different types and its relation to learners' power of logical reasoning.

\section{Relevant literature}

\section{On private speech, reasoning, and higher order thinking enhancing techniques}

As to Berk (1992), private speech is "a critical intermediate stage in the transition from external social communication to internal self-direction and as the cornerstone of all higher cognitive processes, including selective attention, voluntary memory, planning, concept formation and self- reflection" (cited in Fernyhough \& Lloyd, 1999, p. 34). Accordingly, for Vygotsky (1978), the advent of private speech at about 3 years of age initiates in primary socialized speech, which steadily divides into two functionally particular types: speech applied in order to communicate with others and speech only directed at the self. As to Stanley (2011), "since private speech branches off from social speech, it becomes thought spoken out loud" (p.16) and "an externalized self-monitoring system, that plans, directs and controls behavior" (Bivens \& Berk, 1990, p. 444).

Until the 1980s, Vygotsky's ideas about the private speech role as a mediational tool in child development was not extended to second language (L2) acquisition. Lantolf and Frawley were among the first who started working on private speech in the domain of adults' second language acquisition (SLA). The studies conducted by Lantolf and Frawley (1984), as well as Frawley and Lantolf (1985) showed that picture narration tasks in these studies explored probable parallels between Vygotsky's conclusions for 
children and the private speech used by L2 learners. Regarding the production of private speech, Frawley and Lantolf (1985) found that adult English as a second language (ESL) learners and native English-speaking children showed parallel behavior. They were engaged in the picture narration task and they produced a considerable amount of private speech in order to maintain or regain self-regulation in the task but both groups had trouble completing these tasks. Though, the sources of the difficulty were not the same (i.e., children could not organize their narration, whereas the ESL learners' problems were in their lack of skill in the language).

In a related study, the likelihood of some parallels between mastery of the communicative L2 use and a reduction in the use of private speech were investigated by Lantolf and Frawley (1984). However, since private speech is extremely situated, they specified that this issue did not suggest that the learner with native-like proficiency would be self-regulated all the time and not require generating any private speech. In a similar vein, the relationship between the L2 proficiency and the use of private speech which was a similar picture narration study was carried out by McCafferty (1994). His findings seem to "support the hypothesis that with increased proficiency, learners' use of private speech diminishes" (p. 131). However, McCafferty concludes that "a number of other factors have been shown to influence private speech production" (p.133). The type of the task, task difficulty (Appel, 1986), the goal of the task, the number of participants involved, task modality, the performance mode of the task, the amount of concern a participant feels about the consequence of the task, and the cultural experience of the participants are among these (McCafferty, 1992). Similarly, private speech was considered as the main focus of Saville-Troike's (1988) research of children operating L2 forms in their private speech that were used in their social speech later.

To direct their own activity, as to Donato (1994), learners talk aloud to themselves while they are ignoring what their partners are saying, or whisper to themselves when they are trying to do problem-solving tasks. It is observed that students whisper self-addressed directives ('wait'), self-addressed negation ('no'), self-addressed questions with hidden referents such as 'how do you say that?, 'how would you say that?, 'how do I say that?'. In fact, the referent of that is being recognized merely to the speaker. Learners repeat new or difficult L2 forms in a form of whispering and translate those forms into their first language for themselves. In addition, they whisper emotional expressions ('oh'), and opening and closing words such as 'Let's see,' 'OK.' 'Now what?'. In such studies, private speech is inspired by the social context; it is realized that it has a self-regulatory function and promotes "linguistic development and the internalization of collective knowledge" (p. 48).

In 'what is called thinking' Heidegger (cited in Peters, 2008) mentions a variety of thinking that has been perceived by philosophers within the Western tradition. Therefore, based on his thoughts, thinking can be considered as:

$\checkmark$ Doxa: forming an opinion or having an idea (opining)

$\checkmark$ Vorstellen: representing a state of affairs (representing)

$\checkmark$ Ratiocination: developing a chain of premises leading to a valid conclusion (reasoning)

$\checkmark$ Problem-solving: scientific thinking (problem-solving)

$\checkmark$ Beriff (Hegel): conceptual or systematic thinking (conceiving) 
Or possibly it is not mistaken if one contemplates reasoning as one of the subdivisions of critical thinking skills because for instance, Watson and Glaser (2002), the creators of the world's frequently used measure of critical thinking, linked it to the following abilities: Inferences drawn from factual statements; recognition of assumptions in a series of statements; interpreting whether conclusions are warranted or not; determine if conclusions follow from information in given statements, and evaluating arguments as being strong and relevant or weak and irrelevant (pp. 21-22).

In fact, part one of this appraisal which is called 'inference' requires one to distinguish among degrees of truth or falsity of inference drawn from given data. Further, part three of this appraisal which is called 'deduction' requires one to decide whether definite conclusions inevitably follow from information in given statements or premises. If these two parts' definitions are compared with the Heidegger's concept of reasoning which was mentioned at the beginning of this part, it can be understood that they are mostly accorded. Another evidence that we can use in order to validate that reasoning can be considered as a subcategory of the huge concept of critical thinking is the Schafersman's (1991) classification of diverse subparts of critical thinking in which he pinpoints 'reasonable thinking' which is described by a dependence on reason to search for and determine reliable knowledge.

There are some studies indicating the relationship between reasoning power and private speech use of the individuals. As to Winsler et al. (2007), self-talk serves to connect words, actions, and ideas and helps planning and critical thinking. Accordingly, Munro (2009) claims that the ability to deliberately attend to the way we think is often designated as reasoning.

Moreover, the development of private speech is influenced by a particular emphasis placed on the knowledge of the language which is regarded as a platform for self-talk. Likewise, language permits the storing and recovery of information that is known cognition, as well as reasoning about what an individual does or does not know which is called metacognition (Winsler et al. 2007).

Smith (2007) observed both the function and the consequences of private speech during a group activity which may result in the activation of one's own mind. He also concluded that the act of uttering a word or phrase can simplify problem solving and attention to a particular aspect of a problem as well.

The study performed by Salmon (2008) took place in two Reggio-inspired schools where contributing teachers considered children's work as part of their teaching. He used some methods in order to make children's thinking observable as they installed the culture and language of thinking in their classrooms through the use of thinking routines. The results showed that thinking routines build up positive views about thinking and learning. In fact, children established metacognitive and critical thinking skills which made them more attentive to situations that call for thinking.

According to Salmon, private speech engages our critical thinking, helps us consider alternatives and consequences, and make reasonable decisions. Private speech is used to control impulses and to think before acting. Reading skills simplify the progress of private speech.

Likewise, Centeno-Cortes and Jimenez Jimenez (2004) have reviewed the literature on private speech, formulating a category exclusively for the function of reasoning during problem-solving tasks, which they called private verbal thinking (PVT). The second 
aspect of their study focused on discovering how PVT occurs for three different groups of Spanish speakers: native speakers with a high degree of proficiency in English and two groups of American university students, one at advanced language proficiency level and one at intermediate language proficiency level. The participants had to answer a number of challenging questions of a general nature in Spanish. Findings showed numerous forms of self-regulatory PVT. Moreover, PVT was found to follow particular patterns during reasoning. Additionally, the language of thought for PVT proved to be exclusively Spanish for all. Both the advanced and intermediate L2 speakers of Spanish used both Spanish and English when solving the problems, but the advanced speakers tried explicitly to maintain Spanish for thinking. Overall, the researchers suggest, following Ushakova (1994) that it is unlikely that PVT changes completely from the L1 to the L2 even at advanced levels of proficiency. Also, the authors make a plea for teachers to respect the need for students to use their L1 to think through problems. Another contribution of the study concerns the explication of how participants at the different levels of proficiency deployed different forms of PVT in relation to L2 learning.

Concept maps as the first technique of enhancing students' reasoning power are regarded as visual representations of knowledge which allow us to recognize the connection between ideas by generating a graphic map of the relations. They consist of concepts, encircled in boxes, and linking lines demonstrating the relationships between concepts or propositions (Canas, 2003). In constructing concept maps, concept words or phrases are referred to as nodes and are placed in boxes or circles. The connecting structures between the nodes are termed links and are signified by labeled link. The concepts are commonly rank ordered from the most general, most comprehensive concept to the most detailed, least common concept. According to Canas et al. (2003), for concept map construction, a standard process includes defining the topic for focus question, recognizing, and listing the most significant concepts that are linked with that topic, ordering the concepts from highest to lowest, and adding and tagging linking phrases.

Furthermore, Angelo and Cross (1993) designate that concept maps develop student capabilities in definite critical areas. Among these are:

$\checkmark$ The ability to draw reasonable inferences from observations.

$\checkmark$ The ability to synthesize and integrate information and ideas.

$\checkmark$ The ability to learn concepts and theories in the subject area.

In a study, Carrell et al. (1989) investigated the usefulness of text mapping techniques in improving second language reading as a good alternative to traditional prereading and postreading activities. In so doing, they used semantic mapping as a tool in order to present the important vocabulary of the passage to be read and to provide the teacher with a tool to assess the students' prior knowledge of the topic. Furthermore, as the result of incorporating concept mapping technique into reading or postreading phase, the learners learned to display interrelationships prevailing in the passage by recognizing the main ideas and putting them in circles or boxes, as well as forming the connection between ideas and putting them in circles or boxes (Ghanizadeh, 2007).

Besides, as to Pintrich and De Groot (1990), learners' self-regulated learning skill is regarded as one of the powerful factors amongst cognitive ability to raise meaningful 
understanding. As Corno and Mandinach (1983) hold, those who have weak selfregulated learning skill are less competent to guide their own learning. Consequently, they take less advantage of their learning environment. Therefore, it can be concluded that using concept map strategy to develop learners' metacognitive skill can be considered as an influential means to stimulate self-regulation learning skills. It will support learners to be engaged in the meaningful learning in the long run.

Similarly, Talebinezhad and Negari (2007) investigated the influence of concept mapping as a learning strategy on EFL learners' self-regulation in writing classes. Their findings established that concept mapping enhances students' self-regulation.

The researchers of the study assume the effectiveness of concept mapping on enhancing learners' reasoning, based on Khodadady and Ghanizadrh (2010) who contend that concept mapping is regarded as organizational tools such that concept mapping scaffolds a variety types of reasoning about content, make students think critically about the content of whatever they study. They maintain that the application of this technique to increase students' reasoning ability while reading requires "assessing arguments and statements, deducing conclusions and hypotheses, detecting inconsistencies and common mistakes in reasoning, and making inferences" (p. 52). In fact, as to Khodadady and Ghanizadeh, it can be asserted that there is a range of properties inherent in concept mapping which may help to the improvement of learners' higher order ability. All concept map qualities fall effectively within higher order abilities related with making meaning, deduction, argument evaluation, and interpretation, all of which are revelations of reasoning ability.

The second technique of enhancing higher order thinking used in this study was argumentation. To give an argument means to try to persuade someone by giving worthy reasons (Ghanizadeh \& Mirzaee, 2012).

As to Bowell and Kemp (2005), an argument has the following structure:

$\triangleright$ a set of assumptions or premises;

$>$ a method of reasoning or deduction;

$\triangleright$ a conclusion or point.

The premises can be considered as any statement that we have to create which are not themselves confirmed at the moment. Premises may be undeniable pieces of knowledge; or they may be propositions that we make for the sake of argument. In fact, they are the preliminary ideas of an argument. Some premises are definitions; some others are factual declarations about things. For instance, ' $\mathrm{X}$ is a book' is regarded as a factual declaration about a thing. It is depending on whether it is true or false. Some factual assertions are very straightforward (such as ' $\mathrm{X}$ is a book'); others are more noticeably inductive in character for example, 'most children are allergic to peanuts'. The conclusion is whatever proposition the argument is trying to show. Thus, the conclusion can be a premise in a later argument. Regarding argumentation, Bowell and Kemp believe that we are often faced with arguments that endeavor to convince us, to influence our beliefs and actions, by giving us some reasons to believe this or that, or to act in this way or that. The essential thing to understand here is that an attempt to persuade by argument is "an attempt to provide you with reasons for believing a claim, desiring something or doing something" (p. 5). 
Because of the important role of socio-cultural theory in language acquisition, it seems necessary to investigate the private speech role in the reasoning process of English as a foreign language (EFL) learners in dealing with reasoning-gap tasks. In the current study, higher order thinking enhancing techniques and private speech use were hypothesized to positively influence EFL learners' reasoning ability.

Therefore, the following research questions were investigated in this study:

Q1. Is EFL learners' use of private speech correlated with reasoning?

Q1.1.Do parts of private speech-repetition, translation, question, and filler-enhance advanced EFL learners' reasoning?

Q2. Do higher order thinking enhancing techniques make any statistically significant difference between the reasoning power of the control and experimental groups as determined by their private speech?

Q2.1.Do higher order thinking enhancing techniques make any statistically significant difference between the inductive reasoning of the control and experimental groups as determined by their private speech?

Q2.2. Do higher order thinking enhancing techniques make any statistically significant difference between the deductive reasoning of the control and experimental groups as determined by their private speech?

\section{Method}

The present study is regarded as a quasi-experimental one which includes treatment and pretest/posttest phases.

\section{Participants and setting}

The participants of the current study were chosen based on intact group design (Hatch \& Lazaraton, 1991). They were from both genders, males and females. All of them were attending English RC course, at English Language Teaching major at a University in Iran. It seemed that using the techniques of enhancing higher order thinking ability was more in accordance with the expository texts used to be taught during this course. Students ranged in age from 20 to 32 years old. The data were gathered during their 5 th semester of their Bachelor's program. Students belonged to two university classes, one of them was regarded as the control and another was the experimental group. Besides, for the experimental group, two types of higher order thinking enhancing techniques for their RC class were taught. By discarding the students who were outliers, the researchers selected 30 participants for each group. All of them were non-native speakers of English in Iran whose first language was Persian. English students in Iran should pass four RC courses during the four years of Bachelor of Art (B. A.) graduation studies.

In order to be certain of students' homogeneity at the outset of the study, it was required to have the tests to check whether they were homogeneous. Participants needed to be checked for homogeneity in two domains, one was their language proficiency level using the Babel Test, and another was their homogeneity in their power of logical reasoning using the W-GCTA as pretests. Results of the tests showed that participants 
of both groups were homogeneous in their language proficiency, as well as their reasoning power.

\section{Instrumentation}

The Babel English Language Placement Test was the first instrument used throughout the current study. The test was used in order to check the participants' general language proficiency level. Kuder- Richardson (KR-21) Formula was used to measure the reliability index of the current test which was reported as .75 .

The second instrument was the W-GCTA used for both pretest and posttest. There are five different sections included in the WGCTA. They are specially designed in order to check every learner's ability to think analytically and logically. The five sections are as follows (Watson \& Glaser, 2010):

\footnotetext{
$\checkmark$ to make correct inferences

$\checkmark$ to recognize assumptions

$\checkmark$ to make deductions

$\checkmark$ to come to conclusions

$\checkmark$ to interpret and evaluate arguments
}

The two subsections of making inference and deduction were chosen for the purpose of this study including appropriate reasoning-gap tasks. Students were required to do the tasks in parts one (number 1 to 16 ) and three (number 33 to 48 ) only (because these two parts were in accordance with the purpose of the study to measure learners' power of logical reasoning in order to check their deductive and inductive reasoning after the treatment). Therefore, tasks were arranged from number one up to number 32 in which from number one up to number 16 inference making tasks were put. Deduction part started from the task 17 up to the task 32. Attached to each test paper was an answer sheet. For the tasks one to 16 answers were in the multiple choice format in which there were five alternatives. Alternatives for these tasks started with True, Probably True, Insufficient Data, Probably False, and False. Each student was provided with a copy of an answer sheet and s/he was told to choose the best options on the answer sheet. The instruction for each part of the questionnaire was written on the question paper. The students were also told about the instruction for each part of the questionnaire. Moreover, for the first section of the questionnaire, the students were asked to read three reading passages. For the first two passages, there were 10 tasks, five for each. The last passages included six tasks. The students were required to decide which option could be best suited based on the content of the reading text.

In the second part, each task included some premises followed by several proposed conclusions. In order to do such tests, students should consider the statements in each exercise as true without exception. After reading the conclusion below the statement, if the students think that it necessarily follows from the statements given, they can make a black mark under conclusion follows in the appropriate place on the answer sheet. If the students think it is not a necessary conclusion from the statements given, they should put a black mark under conclusion doesn't follow, albeit they may believe it to be true based on their general knowledge. 
Besides, the test required to be validated again. To determine the validity of the two subscales of W-GCTA that is, inference making and deduction, a confirmatory factor analysis (CFA) utilizing the LISREL 8.50 statistical package was performed. Each module went through CFA separately. A number of fit indices were examined to evaluate the model fit. It can be concluded that the model had a moderate fit regarding these two subtests. Figures 1 and 2 present the results of making the two subsections of W-GCTA valid.

In this study, the total reliability of this test was measured by Cronbach's alpha to verify the reliability of the questions used which was found to be 0.77 .

\section{Procedure}

The present study was carried out in 12 sessions during an academic semester. Tables 1 and 2 present the summaries of treatment for the experimental group during these sessions. As mentioned before, concept mapping and argumentation are regarded as two higher order thinking enhancing techniques.

The texts were chosen for the two groups. The tests conducted and the numbers of sessions were identical for both groups. Six reading texts were selected to teach, three of them were chosen from among their course book (i.e., Inside Reading IV by Richmond, 2009). And three others were IELSTS expository texts selected by the researchers. Having worked on the first three texts based on the instructions provided by the teacher, students were asked to fill in the blanks of the concept maps provided for them in order to be more familiar with concept mapping. For the next three reading texts, students were required to draw their own concept maps based on the instructions and their previous experiences about concept mapping. Having finished working on concept mapping, the students were getting familiar with the argumentation technique and how they can determine premises and conclusions in the texts in line with the recognition of argument structures by Bowell and Kemp (2005).

Finally, in the twelfth session which was regarded as the last session of carrying out the process of data collection, the participants were asked to answer the 32 questions of the W-GCTA. The reason for selecting this type of questionnaire for the participants

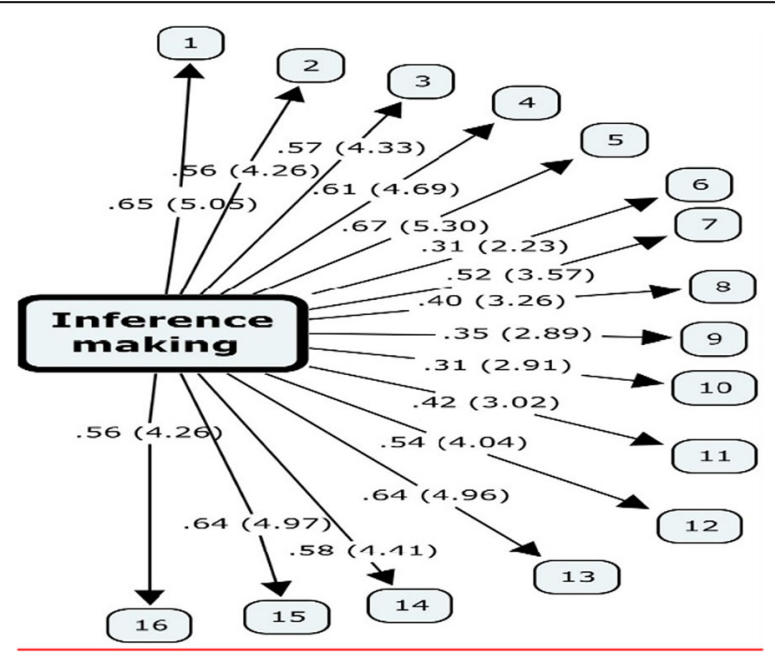

Fig. 1 The schematic representation of inference-making and the corresponding items 


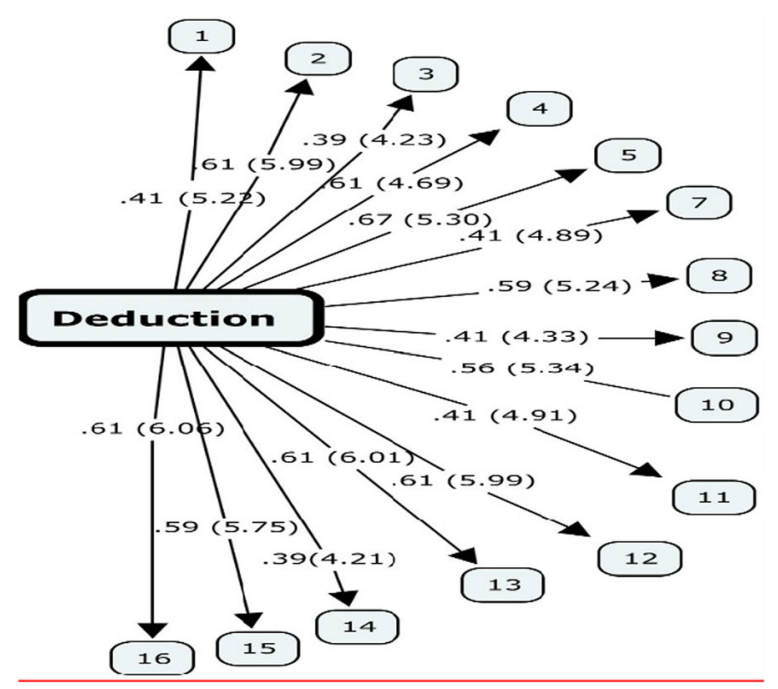

Fig. 2 The schematic representation of deduction and the corresponding items

of this study was that these types of questions were recommended, since according to McCafferty (1994), if the tasks are difficult, the probability of producing private speech will be higher. In general, as to Duncan and Cheyne (2002), the same has been found in children' production of private speech in which children produced more private speech when working on difficult tasks compared to easier tasks, a pattern that supports that private speech is regarded as a form of thinking and a means of problemsolving. The present study investigated this effect with an adult sample. Therefore, the W-GCTA was regarded as possessing the appropriate tasks in this regard.

At the time of the exam, the participants were provided with a pen and a piece of paper, and they were told to use them in the case of need. Students were aware of the fact that they could use their pen and paper but they were also told that using pen and paper would subtract a point from them. Since pen and paper could serve as mediational artifacts that could facilitate their thinking process (Centeno-Cortes \& Jimenez Jimenez 2004). So, the students were implicitly discouraged from using this external aid instead of private speech. It was believed that this tactic would foster the production of private speech. The questionnaire consisted of 80 questions divided into five parts: (1) inference making, (2) recognition of assumptions, (3) deduction, (4) interpretation, and (5) evaluation of arguments. The students were required to do the tasks in parts one (number one to 16) and three (number 33 to 48) only (because these two parts were in accordance with the purpose of the study to measure learners' power of logical reasoning). Extra questions in the W-GCTA (i.e., part two: recognition of assumptions, part

Table 1 A Summary of Treatment Sessions for Concept Mapping

\begin{tabular}{ll}
\hline Session 1 & Pretest for checking students' language proficiency \\
Session 2 & Pretest for checking students' power of logical reasoning \\
Session 3 & Introducing main and supporting ideas for single paragraphs \\
Session 4 & Introducing main and supporting ideas of multi paragraph passages \\
Session 5 & Drawing concept map \\
Session 6 & Drawing concept maps based on step by step procedure they were provided with
\end{tabular}


Table 2 A Summary of Treatment Sessions for Argumentation

\begin{tabular}{ll}
\hline Sessions $7 \& 8$ & Introducing concept of argumentation and its introductory aspects \\
Sessions $9 \& 10$ & Indicating premises and conclusions more skillfully by providing them with more examples \\
Session 11 & $\begin{array}{l}\text { Checking and discussing the students' understanding of premises and conclusions } \\
\text { throughout the whole class }\end{array}$ \\
\hline
\end{tabular}

four: interpretation and part five: evaluation of arguments) were omitted and two other sections (i.e., inference making and deduction) were kept.

In order to consider the ethical value of the study, the participants were aware that the results of the study will be used in a language research. The process of scoring for them was that they obtained one point for their correct answer to each question, they got no points for those answers which were incomplete or wrong, and one point was deduced if they had used paper and pen to discover the answer. Consequently, although the participants were told they were free to use pen and paper during problem-solving, since as to Centeno-Cortes and Jimenez Jimenez (2004), these tools were regarded as mediational artifacts (object regulation) to make their thinking process during solving tasks easy, by deducting a point for using them the research was implicitly discouraging them from using these tools instead of private speech.

The tasks students did, were considered as posttest tasks. Approximately, 60 min' time lasted for taking the test. The participants were comprehensively briefed on what exactly they were supposed to do in this session. The participants' private speech were audiotaped in an almost quiet lab with few distractions, through a set of personal computers and a headset for every participant individually while they were engaging in solving the reasoning-gap tasks in two sessions for the two groups of control and experimental, separately. During this process, all participants were audio-taped. A stereo headset was adjusted to the participants' heads and connected to the audio port of the computer cases. It is worthy of note that students did not hear anything through the headset but it was assumed that when participants' ears were covered, in order to hear their private speech to analyze the tasks, they had to produce louder voices. Additionally, the recording level and volume were attuned so that the software could detect even the lowest sounds. In this way, high-quality digital recordings were obtained.

\section{Data analysis}

In analyzing data obtained from audio taped materials, the researchers, in line with Ohta (2001) and Sonmez (2011), divided private speech of the second language learners into four main types of repetition, translation, filler, and question. Additionally, the protocol produced by learners in the posttest session were coded and analyzed. As to Diaz and Berk (1992), appropriate procedures for classification of private speech should

Table 3 Students' Descriptive Statistics to Check Homogeneity of Proficiency

\begin{tabular}{lllllr}
\hline & Groups & $n$ & $M$ & SD & SE(M) \\
\hline Babel & Control & 30 & 86.53 & 7.20 & 1.31 \\
& Experimental & 30 & 82.60 & 13.05 & 2.38 \\
\hline
\end{tabular}


Table 4 Independent Samples T-Test to Check Students' Homogeneity of Proficiency

\begin{tabular}{|c|c|c|c|c|c|c|c|c|c|c|}
\hline & & \multicolumn{2}{|c|}{ Levene's Test } & \multicolumn{7}{|c|}{$t$-test for Equality of Means } \\
\hline & & \multirow[t]{2}{*}{$F$} & \multirow[t]{2}{*}{ Sig. } & \multirow[t]{2}{*}{$t$} & \multirow[t]{2}{*}{$d f$} & \multirow[t]{2}{*}{ Sig. } & \multirow[t]{2}{*}{ M } & \multirow[t]{2}{*}{ SE } & \multicolumn{2}{|l|}{$95 \% \mathrm{Cl}$} \\
\hline & & & & & & & & & Lower & Upper \\
\hline \multirow[t]{2}{*}{ Babel } & Equal variances assumed & 15.27 & .00 & 1.44 & 58 & .15 & 3.93 & 2.72 & 1.51 & 9.38 \\
\hline & Equal variances not assumed & & & 1.44 & 45.14 & .15 & 3.93 & 2.72 & 1.54 & 9.41 \\
\hline
\end{tabular}

depend on some specific research questions being explored and coding systems should be specifically designed concerning the hypotheses being tested.

Each participant's recorded private speech while performing the tasks were listened carefully by the researchers, two times. In the first time, they were listened in order to check whether any one of them had produced private speech or not. In the second time, those who had produced private speech were listened one more time in order to analyze their speech and categorize their voices into appropriate categories, (i.e., whether they were of repetition, translation, filler, or question). Having coded the data, the researchers counted the frequency of each type of private speech produced, and, did some related and essential analysis. Also, before putting data in the statistical package for the social sciences (SPSS) software in order to analyze them statistically, the researchers wanted two more raters who were their students to kindly consider the data again in order to be sure of the identification of various types of private speech and the sound analysis.

The present researchers dealt with the recorded data by transcribing them completely. The transcription conventions are listed below.

As to Diaz et al. (1992) and Feigenbaum (1992), the utterance is the unit of analysis in most private speech research. It is defined as a complete sentence, a sentence fragment, a clause with deliberate markers of closing, a conversational turn, or any sequence of speech which is detached from another by at least $2 \mathrm{~s}$, temporally. Diaz et al. hold that no temporal or semantic discontinuities were included in an utterance. A temporal discontinuity contains a pause of at least $2 \mathrm{~s}$. A semantic discontinuity comprises any significant change of content. Moreover,many other researchers including Appel and Lantolf (1994), Lantolf and Frawley (1984, 1985), and McCafferty (1992, 1994a) in the socio-cultural framework applied utterances as the unit of analysis. Therefore, in this study utterances were used as the unit of analysis as well.

In fact, the impetus of employing private speech coding and categorization in this study was in line with Cohen and Upton's (2006) ideas that "the act of reading a text to understand it and that of taking a test about the text involve cognitive processes that are not for the most part observable, nor are the strategies deployed by the reader/test taker for the purpose of accomplishing these activities" (p.11). As to Cohen and Upton, in order to get the best result conceivable of what readers do while they are reading test prompts and answering to test items, verbal protocols are typically regarded as an instrument of choice.

Table 5 Students' Descriptive Statistics to Check Students' Homogeneity of Reasoning

\begin{tabular}{llllll}
\hline & Pretest control experimental & $n$ & $M$ & $S D$ & SE(M) \\
\hline Pretest & 1.00 & 15 & 12.83 & 2.24 & .649 \\
& 2.00 & 15 & 14.00 & 3.86 & 1.11 \\
\hline
\end{tabular}


Table 6 Independent Samples T-Test to Check Students' Homogeneity of Reasoning

\begin{tabular}{|c|c|c|c|c|c|c|c|c|c|c|}
\hline & & \multicolumn{2}{|c|}{ Levene'sTest } & \multicolumn{7}{|c|}{ t-test for Equality of Means } \\
\hline & & \multirow[t]{2}{*}{$\bar{F}$} & \multirow[t]{2}{*}{ Sig. } & \multirow[t]{2}{*}{$t$} & \multirow[t]{2}{*}{$d f$} & \multirow[t]{2}{*}{ Sig. } & \multirow[t]{2}{*}{$M$} & \multirow[t]{2}{*}{ SE } & \multicolumn{2}{|l|}{$95 \% \mathrm{Cl}$} \\
\hline & & & & & & & & & Lower & Upper \\
\hline \multirow[t]{2}{*}{ Pretest } & Equal variances assumed & 1.85 & .18 & .90 & 22 & .37 & 1.16 & 1.29 & 3.84 & 1.50 \\
\hline & Equal variances not assumed & & & .90 & 17.69 & .37 & 1.16 & 1.29 & 3.88 & 1.54 \\
\hline
\end{tabular}

Therefore, having discarded those participants who did not produce private speech as it was revealed in the first listening to the recorded data, other audio-recordings from each group were selected, transcribed, and analyzed by the researchers with the help of two raters. The following coding system was considered for the different events included in their private speech:

Private speech: repetition (R), translation (T), filler (F), question (Q).

First language use (L)

Incomprehensible or inaudible word (IC)

As Green (1998) asserts, protocols should be transcribed exactly as they are. It means that they should not be modified by adding or substituting words.

\section{Transcription instances}

$\triangleright$ The following is a sample transcription of the inference and deduction parts of W-GCTA. Different parts were extracted from different learners.

S10: Mr. Brown, who lives in the town of Salem, was brought before the Salem municipal court for the sixth time in the past month on a charge of keeping his pool hall open after 1a.m [R] [IC]. He again admitted his guilt and was fined the maximum, $\$ 500$, as in each earlier instance [R] Uhh [F].

S2: Rice and celery [R] Umm [F] must have a good deal of moisture in order to grow well, but rye and cotton grow best [R] Kodamha behtar roshd mikonanad? [Q] where it is relatively dry $[\mathrm{R}][\mathrm{T}]$.

\section{Results}

Independent samples $t$-tests, Pearson product moment correlation, and one-way repeated measures (ANOVA) were run using SPSS version 22 for obtaining the results of the study. Alpha level was set at .05.

Table 7 Results of Correlation between Reasoning power and Private Speech

\begin{tabular}{llll}
\hline & & $\mathrm{R}$ & $\mathrm{PS}$ \\
\hline $\mathrm{R}$ & Pearson Correlation & 1 & $.47^{* *}$ \\
& Sig. (2-tailed) & & .00 \\
$\mathrm{~N}$ & 60 & 60 \\
$\mathrm{NS}$ & Pearson Correlation & $.47^{* *}$ & 1 \\
& Sig. (2-tailed) & .00 & \\
& $\mathrm{~N}$ & 60 & 60 \\
\hline
\end{tabular}

${ }^{* *}$ Correlation is significant at the 0.01 level (2-tailed) 


\section{Results of the pretests}

In order to achieve a more reliable data, those students who were 3 standard deviations below or above the mean were first omitted from the study. Then, the $t$-tests for homogeneity were run to compare the Babel Test scores for the experimental and control groups in order to check the students' language proficiency levels. The results showed that there was not a significant difference in scores for the experimental group $(M=$ $82.60, S D=13.05)$ and the control group, $(M=86.53, S D=7.20) ; t(45.147)=1.44, p$ $=.000$ (two - tailed). The magnitude of the differences in the means was (mean difference $=3.93,95 \% \mathrm{Cl}$ [1.54 to 9.415]). Therefore, it can be concluded that the students in the control and experimental groups had no significant difference regarding their language proficiency (Tables 3 and 4).

In order to check that students' homogeneity of their reasoning power, they were given the W-GCTA as pretest. The results indicated that there was not a significant difference in scores for the experimental group $(M=14.00, S D=3.86)$ and the control group, $(M=12.83, S D=2.24) ; t(17.696)=0.37, p=.000$ (two $\cdot$ tailed). The magnitude of the differences in the means was (mean difference $=1.16,95 \% \mathrm{Cl}$ [1.54 to 3.88]). $\mathrm{Re}$ sults indicated that the students in the control and experimental groups had no significant difference regarding their power of logical reasoning (Tables 5 and 6).

According to the first research question stating 'Is EFL learners' use of private speech correlated with reasoning?' the relationship between the private speech use and the reasoning power of the EFL students was investigated using Pearson product-moment correlation coefficient. Preliminary analyses were performed to ensure no violation of the assumptions of normality, linearity, and homoscedasticity. The results revealed that there was a strong, positive correlation between the two variables, $r=.47, n=60, P$ $<.05$, with high levels of private speech use associated with high levels of reasoning power (Table 7).

Considering the first sub-research question, 'do parts of private speech-repetition, translation, question, and filler-enhance advanced EFL learners' reasoning?', according to Ohta (2001) and Sonmez's (2011) categorizations of private speech, the following private speech categorization based on Table 8 was used to analyze data.

Table 9 illustrates the frequencies of occurrences of different types of private speech in the control and experimental groups in order to make a comparison and find the relationship between private speech type frequencies to see whether its different categorization makes any statistically significant difference in EFL learners' reasoning.

The frequency of private speech used by different participants in the two groups was different in the way that totally, the amount of private speech produced by the EFL learners who belonged to the experimental group $(n=1097)$ was significantly higher than the private speech produced by those of the control group $(n=620)$. Of course, the amount of private speech produced was not the same among all individuals of the

Table 8 Private Speech Study and Its Accompanying Categorization

\begin{tabular}{llll}
\hline Citation & Private speech categorization & Task & Setting \\
\hline Ohta (2001) & 1. Repetition & Reasoning-gap tasks & Lab setting \\
Sonmez (2011) & 2. Translation & & \\
& 3. Filler & & \\
& 4. Question & & \\
\hline
\end{tabular}


Table 9 Comparison of the Types of Private Speech and Reasoning Power in Control and Experimental Groups

\begin{tabular}{lll}
\hline Private speech type frequencies & Control group & Experimental group \\
\hline Private speech & 620 & 1097 \\
Repetition & 347 & 654 \\
Translation & 126 & 209 \\
Filler & 82 & 126 \\
Question & 65 & 108 \\
\hline
\end{tabular}

same group. In the other words, some participants in both groups did not produce private speech at all. In fact, as to Berk (1992), this point is in accordance with the findings of the experimental studies on children private speech, in which it is usual for only about half of the children in a sample to truly produce private speech.

Furthermore, as it was depicted in Table 9, the frequency of occurrences of different categorizations of private speech was different among individuals in the control and experimental groups. The frequency of repetition as the first category of private speech in the control group was $(n=347)$ and in the experimental group was $(n=654)$. Besides, the frequency of occurrences of the second category (i.e., translation) was $(n=126)$ in the control group and it was $(n=209)$ in the experimental group. Regarding filler as the third category, EFL learners in the control group produced $(n=82)$ and in the experimental group they produced $(n=126)$. The last category was question which had the least frequency. The frequency of this part was $(n=65)$ in the control and $(n=108)$ in the experimental group. Additionally, since the amount of private speech produced by the experimental group was generally higher than private speech in the control group, it seems that higher order thinking enhancing techniques made them create more private speech in order to enhance their reasoning. The amount of private speech produced by every individual across different groups varied. It means that different individuals performed differently regarding private speech production when they dealt with reasoning-gap tasks. For example, student 6 in the experimental group produced the most amount of private speech $(n=51)$ and student 21 of the control group produced the most amount of private speech in the tasks $(n=46)$. Student 27 in the control group produced the least amount of private speech $(n=3)$ and student 21 of the experimental group produced the least amount of private speech for the tasks $(n=11)$. The use of private speech is an indication of difficulty with the task (Frauenglass \& Diaz 1985). In other words, participants who struggled with an experimental task tended to self-verbalize, whereas participants who had no difficulty tended not to.

Tables 10 and 11 illustrate the frequency of occurrences of the participants' private speech relating to different groups, as well as its descriptive statistics.

Table 12 presents the result of ANOVA conducted to compare scores on the production of private speech types and its impact on the EFL learners' reasoning scores. As

Table 10 The Most and the Least Frequent Private Speech in accordance with Groups

\begin{tabular}{llll}
\hline $\begin{array}{l}\text { Participants of } \\
\text { experimental group }\end{array}$ & $\begin{array}{l}\text { Experimental group private } \\
\text { speech frequency }\end{array}$ & $\begin{array}{l}\text { Participants of } \\
\text { control group }\end{array}$ & $\begin{array}{l}\text { Control group private } \\
\text { speech frequency }\end{array}$ \\
\hline S6 & 51 & S21 & 46 \\
S21 & 11 & S27 & 3 \\
\hline
\end{tabular}


Table 11 Descriptive Statistics of Four Categories of Private Speech

\begin{tabular}{llll}
\hline Private speech & $M$ & SD & $n$ \\
\hline Repetition & 16.63 & 7.52 & 60 \\
Translation & 5.58 & 4.06 & 60 \\
Filler & 3.46 & 2.65 & 60 \\
Question & 2.88 & 2.82 & 60 \\
\hline
\end{tabular}

indicated in Table 12, there was a statistically significant difference for private speech use among the participants in accordance with their reasoning power, Wilks' Lambda $=.21, F(3.00)=70.99, P<.05$, multivariate partial eta squared $=.78$. It means that different categories of private speech made significant changes in the students' reasoning power.

In order to check whether 'repetition makes any statistically significant difference between the reasoning of control and experimental groups' both groups were checked to see whether there is any statistically significant difference between them regarding their reasoning as determined by the first category of private speech (i.e., repetition). An independent samples $t$-test was run. Table 13 shows the $t$-test results for this analysis subsequently.

The results indicated that there was a significant difference in scores for the control group $(M=11.56, S D=4.98)$ and the experimental group, $(M=21.70, S D=6.11) ; t(58)$ $=7.03, p=.000$ (two - tailed). The magnitude of the differences in the means was (mean difference $=10.13,95 \% \mathrm{Cl}$ [13.01 to 7.25$]$ ). Therefore, the results specified that the students in the control and experimental groups had a significant difference regarding their reasoning as determined by repetition.

In order to check whether 'translation makes any statistically significant difference between the reasoning of control and experimental groups' both groups were analyzed to regarding their reasoning as determined by the second category of private speech (i.e., translation); an independent samples $t$-test was run. Table 14 shows the $t$-test results for this analysis.

The results indicated that there was a significant difference in scores for the control group $(M=4.20, S D=3.01)$ and the experimental group, $(M=6.96, S D=4.52) ; t(50.43)$ $=2.78, p=.00$ (two - tailed). The magnitude of the differences in the means was (mean difference $=2.76,95 \% \mathrm{Cl}[4.76$ to 0.77$])$. Therefore, the results indicated that the students in the control and experimental groups had significant difference regarding their power of reasoning as determined by translation.

Table 12 One-Way Repeated Measures ANOVA to Check the Relationship between Private Speech Categorization and Reasoning Power

\begin{tabular}{llllllll}
\hline \multicolumn{1}{l}{ Multivariate Tests } \\
\hline Effect & Value & $F$ & Hypothesis $d f$ & Error df & Sig. & Partial Eta Squared \\
\hline Privatespeech & Pillai's Trace & .78 & $70.99^{\mathrm{b}}$ & 3.00 & 57.00 & .00 & .78 \\
& Wilks' Lambda & .21 & $70.99^{\mathrm{b}}$ & 3.00 & 57.00 & .00 & .78 \\
& Hotelling's Trace & 3.73 & $70.99^{\mathrm{b}}$ & 3.00 & 57.00 & .00 & .78 \\
& Roy's Largest Root & 3.73 & $70.99^{\mathrm{b}}$ & 3.00 & 57.00 & .00 & .78 \\
\hline
\end{tabular}

aDesign: Intercept Within Subjects Design: privatespeech 
Table 13 Independent Samples T-Test to Check the Effect of Repetition on Reasoning in Control and Experimental Groups

\begin{tabular}{|c|c|c|c|c|c|c|c|c|c|c|}
\hline & & \multicolumn{2}{|c|}{ Levene's Test } & \multicolumn{7}{|c|}{ t-test for Equality of Means } \\
\hline & & \multirow[t]{2}{*}{$F$} & \multirow[t]{2}{*}{ Sig. } & \multirow[t]{2}{*}{$t$} & \multirow[t]{2}{*}{$d f$} & \multirow[t]{2}{*}{ Sig. } & \multirow[t]{2}{*}{$M$} & \multirow[t]{2}{*}{ SE } & \multicolumn{2}{|l|}{$95 \% \mathrm{Cl}$} \\
\hline & & & & & & & & & Lower & Upper \\
\hline \multirow[t]{2}{*}{ Repetition } & Equal variances assumed & .75 & .38 & 7.03 & 58 & .00 & 10.13 & 1.43 & 13.01 & 7.25 \\
\hline & Equal variances not assumed & & & 7.03 & 55.71 & .00 & 10.13 & 1.43 & 13.01 & 7.24 \\
\hline
\end{tabular}

In order to check whether 'filler makes any statistically significant difference between the reasoning of control and experimental groups' both groups were analyzed to see the probable difference between them regarding their reasoning as determined by the third category of private speech (i.e., filler); an independent samples $t$-test was performed. Table 15 displays the $t$-test results for this analysis.

The results designated that there was a statistically significant difference in scores for the control group $(M=2.73, S D=2.75)$ and the experimental group, $(M=4.20, S D=$ 2.38); $t(58)=2.20, p=.03$ (two - tailed). The magnitude of the differences in the means was (mean difference $=1.46,95 \% \mathrm{Cl}[2.79, .13]$ ). Therefore, the results showed that the students in the control and experimental groups had a statistically significant difference regarding their power of reasoning as determined by fillers.

Finally, in order to check whether 'question makes any statistically significant difference between the reasoning of control and experimental groups' both groups were examined to see any significant difference between them regarding their reasoning as determined by the last category of private speech (i.e., question); an independent samples $t$-test was run. Table 16 shows the $t$-test results for this analysis.

The results indicated that there was a statistically significant difference in scores for the control group $(M=2.16, S D=2.61)$ and the experimental group, $(M=3.60, S D=$ 2.89 ); $t(58)=2.01, p=.04$ (two - tailed). The magnitude of the differences in the means was (mean difference $=1.43,95 \% \mathrm{Cl}[2.85, .00]$ ). Therefore, the results showed that the students in the control and experimental groups had a statistically significant difference regarding their power of reasoning as determined by question.

Additionally, in order to check which of the categories of private speech had more effect on learners' reasoning; their $t$-values were compared. With regards to the $t$-value, since repetition had the highest $t$-value $(t=7.03)$, it can be concluded that, it had the highest impact on the learners' reasoning. $T$-value of translation $(t=2.78)$ indicates that after repetition, translation had the highest impact on EFL learners' reasoning. Afterwards, filler and question with the $t$-value of $(t=2.20)$ and the $t$-value of $2.01(t=2.01)$ respectively, had the least effect.

Table 14 Independent Samples T-Test to Check the Effect of Translation on Reasoning in Control and Experimental Groups

\begin{tabular}{|c|c|c|c|c|c|c|c|c|c|c|}
\hline & & \multicolumn{2}{|c|}{ Levene's Test } & \multicolumn{7}{|c|}{ t-test for Equality of Means } \\
\hline & & \multirow[t]{2}{*}{$F$} & \multirow[t]{2}{*}{ Sig. } & \multirow[t]{2}{*}{$t$} & \multirow[t]{2}{*}{$d f$} & \multirow[t]{2}{*}{ Sig. } & \multirow[t]{2}{*}{ M } & \multirow[t]{2}{*}{ SE } & \multicolumn{2}{|l|}{$95 \% \mathrm{Cl}$} \\
\hline & & & & & & & & & Lower & Upper \\
\hline \multirow[t]{2}{*}{ Translation } & Equal variances assumed & 6.44 & .014 & 2.78 & 58 & .00 & 2.76 & .99 & 4.75 & .77 \\
\hline & Equal variances not assumed & & & 2.78 & 50.43 & .00 & 2.76 & .99 & 4.76 & .77 \\
\hline
\end{tabular}


Table 15 Independent Samples T-Test to Check the Effect of Filler on Reasoning in Control and Experimental Groups

\begin{tabular}{|c|c|c|c|c|c|c|c|c|c|c|}
\hline & & \multicolumn{2}{|c|}{ Levene's Test } & \multicolumn{7}{|c|}{ t-test for Equality of Means } \\
\hline & & \multirow[t]{2}{*}{$F$} & \multirow[t]{2}{*}{ Sig. } & \multirow[t]{2}{*}{$t$} & \multirow[t]{2}{*}{$d f$} & \multirow[t]{2}{*}{ Sig. } & \multirow[t]{2}{*}{$M$} & \multirow[t]{2}{*}{ SE } & \multicolumn{2}{|l|}{$95 \% \mathrm{Cl}$} \\
\hline & & & & & & & & & Lower & Upper \\
\hline \multirow[t]{2}{*}{ Fillers } & Equal variances assumed & .09 & .75 & 2.20 & 58 & .03 & 1.46 & .66 & 2.79 & .13 \\
\hline & Equal variances not assumed & & & 2.20 & 56.83. & .03 & 1.46 & .66 & 2.79 & .13 \\
\hline
\end{tabular}

With Regards to the second research question stating that 'do higher order thinking enhancing techniques make any statistically significant difference between the reasoning power of the control and experimental groups as determined by their private speech?' two groups of the EFL learners were analyzed to check their probable differences regarding their reasoning power. Tables 17 and 18 show the descriptive statistics and $t$-test results of the control and experimental groups when they took part in the posttest session, in order to check whether there was any statistically significant difference between these groups regarding their power of reasoning.

An independent samples $t$-test was conducted. Table 18 illustrates, there was a significant difference in scores for the experimental group $(M=20.84, S D=3.57)$ and the control group, $(M=12.60, S D=2.32) ; t(54)=10.35, p=.000$ (two $\cdot$ tailed). The magnitude of the differences in the means was (mean difference $=8.24,95 \% \mathrm{Cl}[9.84,6.65]$ ).

With regards to the first sub-research question stating that 'do higher order thinking enhancing techniques make any statistically significant difference between the inductive reasoning of the control and experimental groups as determined by their private speech?', the control and experimental groups' power of inductive reasoning was considered by their performance on inductive part of reasoning-gap tasks. Tables 19 and 20 depict the results.

An independent samples $t$-test was done in order see if there is any statistically significant difference between the control and experimental groups regarding their inductive reasoning. Findings are shown in Table 20. According to the results, there was a significant difference in scores for the experimental group $(M=9.15, S D=1.76)$ and the control group, $(M=4.00, S D=1.76) ; t(54)=9.5, p=.000$ (two $\cdot$ tailed). The magnitude of the differences in the means was (mean difference $=5.15,95 \% \mathrm{Cl}[6.24,4.06]$ ).

Regarding the second sub-research question stating that 'do higher order thinking enhancing techniques make any statistically significant difference between the deductive reasoning of the control and experimental groups as determined by their private speech?', the control and experimental groups' performance on deduction part of reasoning-gap tasks were examined. Therefore, in order to see whether participants of these groups in posttest have any statistically significant difference in the deductive

Table 16 Independent Samples T-Test to Check the Effect of Question on Reasoning in Control and Experimental Groups

\begin{tabular}{|c|c|c|c|c|c|c|c|c|c|c|}
\hline & & \multicolumn{2}{|c|}{ Levene's Test } & \multicolumn{7}{|c|}{ t-test for Equality of Means } \\
\hline & & \multirow[t]{2}{*}{$F$} & \multirow[t]{2}{*}{ Sig. } & \multirow[t]{2}{*}{$t$} & \multirow[t]{2}{*}{$d f$} & \multirow[t]{2}{*}{ Sig. } & \multirow[t]{2}{*}{ M } & \multirow[t]{2}{*}{ SE } & \multicolumn{2}{|l|}{$95 \% \mathrm{Cl}$} \\
\hline & & & & & & & & & Lower & Upper \\
\hline \multirow[t]{2}{*}{ Question } & Equal variances assumed & .26 & .60 & 2.01 & 58 & .04 & 1.43 & .71 & 2.85 & .00 \\
\hline & Equal variances not assumed & & & 2.01 & 57.40 & .04 & 1.43 & .71 & 2.85 & .00 \\
\hline
\end{tabular}


Table 17 Descriptive Statistics of Students to Check Their Reasoning Power

\begin{tabular}{llllll}
\hline & Posttestce & $N$ & $M$ & SD & SE(M) \\
\hline Posttest & Control & 30 & 12.60 & 2.32 & .42 \\
& Experimental & 30 & 20.84 & 3.57 & .70 \\
\hline
\end{tabular}

reasoning, another independent samples $t$-test was run. Tables 21 and 22 describe the results.

According to the results depicted in Tables 21 and 22, there was a significant difference in scores for the experimental group $(M=11.69, S D=2.70)$ and the control group, $(M=8.60, S D=2.38) ; t(54)=4.54, p=.00$ (two - tailed). The magnitude of the differences in the means was (mean difference $=3.09,95 \% \mathrm{Cl}[4.45,1.72]$ ).

\section{Discussion}

The results of the data analysis to check the probable impacts of different categories of private speech on the EFL learners' reasoning power showed significant differences these categories made on the students' reasoning. As to English (1997), private speech produced by the most and the least proficient reasoners was rather similar in quantity. It means that, both groups of the reasoners involved in nearly the same amount of private speech during working on tasks. Nevertheless, regarding the quality of the private speech production, English believes; however, conspicuous variances between the most proficient and the least proficient reasoners were recorded, with regards to the quality of that private speech. For instance, the most expert problem solvers produced private speech to help them solving tasks showed their attention to the task. English holds private speech utterances produced by the skillful problem solvers referenced the nature of the reasoning tasks and echoed their capability to verbalize conceptual relationships. On the other hand, the private speech produced by less proficient reasoners designated that they did not attend well to the several dimensions of the tasks. Neither these types of private speech seem to assist the problem-solving process.

In a research carried out Duncan and Cheyne (2002), the authors assert that "private speech appears to be more than a stage or phase of ontogenetic development" (p. 901). The findings indicated that "overt self-verbalization continues to play a mediational role in problem-solving and self-regulatory processes during early adulthood" (p. 901).

On the whole, the findings of a variety of studies which indicate that private speech use is greater on difficult tasks than on easier tasks, reveal that private speech is regarded as a form of thinking and a means of problem-solving. The replication of studies based on children's private speech production on the young adults shows the experimental evidence which indicates that the relationship between private speech production and task difficulty continues beyond childhood. In fact, adults as the same

Table 18 Independent Samples T-Test to Check Students' Power of Reasoning

\begin{tabular}{|c|c|c|c|c|c|c|c|c|c|c|}
\hline & & \multicolumn{2}{|c|}{ Levene's Test } & \multicolumn{7}{|c|}{$t$-test for Equality of Means } \\
\hline & & \multirow[t]{2}{*}{$\bar{F}$} & \multirow[t]{2}{*}{ Sig. } & \multirow[t]{2}{*}{$t$} & \multirow[t]{2}{*}{$d f$} & \multirow[t]{2}{*}{ Sig. } & \multirow[t]{2}{*}{$M$} & \multirow[t]{2}{*}{ SE } & \multicolumn{2}{|l|}{$95 \% \mathrm{Cl}$} \\
\hline & & & & & & & & & Lower & Upper \\
\hline \multirow[t]{2}{*}{ Posttest } & Equal variances assumed & 2.58 & .11 & 10.35 & 54 & .00 & 8.24 & .79 & 9.84 & 6.65 \\
\hline & Equal variances not assumed & & & 10.05 & 41.88 & .00 & 8.24 & .81 & 9.90 & 6.59 \\
\hline
\end{tabular}


Table 19 Descriptive Statistics of Students to Check Their Power of Induction

\begin{tabular}{llllll}
\hline & Induction control experimental & $N$ & $M$ & SD & SE(M) \\
\hline Induction & Control & 30 & 4.00 & 1.76 & .32 \\
& Experimental & 30 & 9.15 & 2.29 & .44 \\
\hline
\end{tabular}

as children, have the greater cognitive demands of more difficult tasks. Therefore, they elicit more self-directed speech (Duncan \& Cheyne, 2002).

In another study, El'konin (cited in Diaz \& Berk, 1992) performed a private speech research in which he supports the reasoning process in learners as determined by private speech. He presents analyses of the private speech produced during drawing activity and during solving practical problems.

As the results of the present study indicated, the amount of the private speech production was higher in the experimental than the control group. It seems that the experimental group who received higher order thinking enhancing techniques was more successful in being self-regulated and production of private speech. Consequently, they obtained higher scores in carrying out their reasoning-gap activities.

The amount of private speech production, as well as its categories in this study, is in line with some similar studies. According to Ohta (2001), repetition was the most common form where the learners privately repeated the utterances in the tasks. This was common with the most difficult sentences or those structures they could not understand them. Additionally, Sonmez (2011) claims that private speech can emerge in the form of repetition when "the participants have self-discoveries about some part of their own task, performance, or knowledge" (p. 109). Furthermore, Sonmez asserts, by repetition, learners can make sense of the new information and recover prevailing knowledge from their memory. Moreover, he mentions repetition of the new language forms may contribute participants to establish their thoughts and understand the gaps exist in their performance or knowledge while internalizing new information. Besides, as to Centeno-Cortes and Jimenez Jimenez (2004), "by repeating pieces of discourse, speakers concentrate on the information that seems to be problematic or crucial" (p. 18). Additionally, Frawley (1997) claims that by using repetition, speakers help themselves to concentrate on the problem. Also, Anani and Gordani (2014) contend that "repetition mainly signals the participants' ongoing thought process and is an attempt to take it under control". In fact, "the purpose here is to focus and direct the thought towards the item" (p. 8).

Using translation by the participants during performing tasks can indicate the important role that L1 may play here. Based on Centeno-Cortes and Jimenez Jimenez (2004), having used translation, the learners may realize that the line of reasoning deployed was futile, abandoned it and endeavored to find an alternative path. A breakdown could also be accompanied by a switch in the language used (from L2 to L1).

Table 20 Independent Samples T-Test to Check Students' Power of Induction

\begin{tabular}{|c|c|c|c|c|c|c|c|c|c|c|}
\hline & & \multicolumn{2}{|c|}{ Levene's Test } & \multicolumn{7}{|c|}{$t$-test for Equality of Means } \\
\hline & & \multirow[t]{2}{*}{$F$} & \multirow[t]{2}{*}{ Sig. } & \multirow[t]{2}{*}{$T$} & \multirow[t]{2}{*}{$d f$} & \multirow[t]{2}{*}{ Sig. } & \multirow[t]{2}{*}{ M } & \multirow[t]{2}{*}{ SE } & \multicolumn{2}{|l|}{$95 \% \mathrm{Cl}$} \\
\hline & & & & & & & & & Lower & Upper \\
\hline \multirow[t]{2}{*}{ Induction } & Equal variances assumed & .77 & .38 & 9.50 & 54 & .00 & 5.15 & .54 & 6.24 & 4.06 \\
\hline & Equal variances not assumed & & & 9.32 & 46.61 & .00 & 5.15 & .55 & 6.26 & 4.04 \\
\hline
\end{tabular}


Table 21 Descriptive Statistics of Students to Check their Power of Deduction

\begin{tabular}{lllrll}
\hline & Deduction control experimental & $N$ & $M$ & SD & SE(M) \\
\hline Deduction & Control & 30 & 8.60 & 2.38 & .43 \\
& Experimental & 30 & 11.69 & 2.70 & .53 \\
\hline
\end{tabular}

Sonmez (2011) holds that fillers can be regarded as indicators of the thought process and they help learners avoid distraction. He maintains that the participants use fillers "to signal the ongoing thought process and sometimes to organize the thought process" (p. 121). As Centeno-Cortes and Jimenez Jimenez (2004) hold, fillers can help learners "avoid getting distracted" (p. 18). Anani and Gordani (2014), also, assert that using fillers can give learners abundant time in order to think about the next action they would like to do. Moreover, regarding using question during carrying out reasoninggap tasks Sonmez (2011) contends that asking questions can help the participants "to orient and re-orient themselves to the task" (p. 126).

The results also indicated that the two techniques of concept mapping and argumentation positively and significantly influenced the power of logical reasoning as it was measured by the two subscales of W-GCTA. In other words, the integration of such techniques to the EFL reading classes tended to foster the learners' power of reasoning. Accordingly, the results revealed that the power of logical reasoning was increased through using higher order thinking enhancing techniques. It was proved through running independent samples $t$-test, and as a result, the frequency of reasoning, in general, and inductive, deductive reasoning, in particular, was increased in the experimental group more than the control group who received no treatment.

The researchers of the present study set out to examine the differences between the control and experimental groups based on the current models and theories of learning suggesting that critical thinking enhancing techniques such as concept mapping and argumentation can augment the EFL learners' reasoning power which is regarded as higher order thinking. In other words, the findings of the current study lend enough support to the claim that reasoning as a subpart of the general concept of critical learning (W-GCTA, 2010) could be enhanced by means of critical thinking enhancing techniques such as concept mapping and argumentation (Ghanizadeh \& Mirzaee, 2012). Regarding argumentation, for instance, Kelly and Bazerman (2003) endeavored to understand the ways students engaged in the scientific reasoning associate general theoretical claims to complete data in making evidence. Besides, as to Hillocks (2010), arguments are regarded as the single most important component in the critical thinking. We produce an argument when for thinking that a claim is true, we give a reason. What is more, according to Hillocks, "formal argument is a line of reasoning that attempts to prove by logic" (p. 305). In fact, argument is at the heart of critical thinking and academic discourse. Likewise, as to Dabaghi et al. (2012), language tasks which

Table 22 Independent Samples T-Test to Check Students' Power of Deduction

\begin{tabular}{|c|c|c|c|c|c|c|c|c|c|c|}
\hline & & \multicolumn{2}{|c|}{ Levene's Test } & \multicolumn{7}{|c|}{$t$-test for Equality of Means } \\
\hline & & \multirow[t]{2}{*}{$\bar{F}$} & \multirow[t]{2}{*}{ Sig. } & \multirow[t]{2}{*}{$t$} & \multirow[t]{2}{*}{$d f$} & \multirow[t]{2}{*}{ Sig. } & \multirow[t]{2}{*}{$M$} & \multirow[t]{2}{*}{ SE } & \multicolumn{2}{|l|}{$95 \% \mathrm{Cl}$} \\
\hline & & & & & & & & & Lower & Upper \\
\hline \multirow[t]{2}{*}{ Deduction } & Equal variances assumed & .00 & 1.00 & .54 & 54 & .00 & 3.09 & .68 & 4.45 & 1.72 \\
\hline & Equal variances not assumed & & & 4.50 & 50.31 & .00 & 3.09 & .68 & 4.47 & 1.71 \\
\hline
\end{tabular}


necessitate greater criticality on the part of learners might request more critical thinking; therefore, one aspect of the critical thinking simply refers to people's reasoning inductively and deductively, and to infer sound conclusions from ambiguous statements (Freeley \& Steinberg, 2000). What is more, as Dabaghi et al. hold, one of the domains in which critical thinking might open up a related line of examination is the argumentative genre because argumentation is cognitively-demanding.

Regarding the probable impact of concept mapping on the EFL learners' power of reasoning, as to Ghanizadeh and Mirzaee (2012), organizational tools including concept mapping scaffold various forms of reasoning about content and engage students in thinking critically about the content of whatever they study. Jonassen et al. (1998) claim that applying critical thinking while reading requires evaluating arguments and statements, deducing conclusions and hypotheses, noticing inconsistencies, and common mistakes in reasoning, and making inferences. Indeed, there are numerous properties intrinsic in concept mapping which may help the improvement of learners' critical thinking ability. Ghanizadeh and Mirzaee (2012) believe that "extracting the main ideas or concepts of the passage and enclosing them in squares or boxes may help them conceptualize and organize text ideas and information into a coherent whole" (pp. 57-58). In fact, by labeling the arrows in the concept map the learners can recognize the rhetorical functions like causeeffect, compare-contrast, arguments, etc., as well as deciding upon deductively and inductively valid arguments. This, in turn, can help learners to discover main ideas, to differentiate between salient and subsidiary points or arguments, and to detect the text structure. To Ghanizadeh and Mirzaee, "all the above-mentioned qualities fall adequately within higher-order abilities associated with making meaning from text and reading between lines, such as inference-making, deduction, argument evaluation, and interpretation, all of which are manifestations of critical thinking ability" (p. 58).

Besides, the results were in line with Wheeler and Collins's (2003) findings that concept mapping is effective in helping nursing students improve critical thinking skills. The results were also consistent with previous research by Ghanizadeh (2007) on concept mapping in which she considers concept mapping as an assessment tool of EFL reading comprehension which investigated test-taking strategies of concept mapping via think-aloud technique. The results of her study revealed that among the strategies related to higher-order abilities, proposition synthesizing, and inference-making were the most regular ones. Furthermore, various properties intrinsic in concept mapping may have added to the improvement of learners' critical thinking ability.

\section{Conclusion}

The present study investigated the role of the advanced EFL learners' private speech production characterized as being the externalization of the process of reasoning during carrying out reasoning-gap tasks. It was observed that while performing the reasoning-gap tasks applied in this study, the EFL learners produced four types of private speech, repetition, translation, filler, and question, in both their L1 and L2. The results, also, indicated that all these four types of private speech enhanced learners' reasoning. Besides, this study scrutinized the probable differences between the two groups of control and experimental in order to check their private speech types and 
reasoning power. The results revealed that private speech production was mostly produced by students in the experimental group rather than the control group. Moreover, results showed that the reasoning of the experimental group was more powerful than that of the control group. With regards to the effect of L1 on learners' reasoning, analyzing data showed that the learners employed the L2 mainly while reading and for repetitions of parts of the questions, proper names, etc., while they were performing reasoning tasks. The data collected from the participants' private speech indicated a shift to the L1 in the participants when the problem became difficult.

The results of the data analysis to check the probable impacts of private speech on the EFL learners' reasoning power showed significant differences private speech types made on students' reasoning. Furthermore, in the current study, private speech produced by the experimental group and their corresponding reasoning power indicated that using higher order thinking enhancing techniques could improve the learners' quality of reasoning, as well as their power of self-regulation. In fact, such learners who were treated by the techniques of enhancing reasoning paid more attention to the task, and they were more self-regulated. On the other hand, those learners who did not receive treatment, paid less attention to the reasoning-gap tasks, being less self-regulated, and consequently, produced less amount of private speech. In this regard, Duncan and Cheyne (2002) remark private speech plays a mediational role in problem-solving and self-regulatory processes. Therefore, private speech can be regarded as a form of thinking and a means of problem-solving. In fact, since critical thinking is an essential skill for education and even life, the techniques of enhancing higher order thinking can help learners to achieve greater academic and life success. As to Wright (2002), the complexity of modern life requires increasing and deploying reasoning abilities. Simple thinking cannot be of help in solving the problems of complicated situations, such situations need higher order intelligent capabilities including multifaceted critical thinking. These results, as well as the results of the previous studies on the role of private speech, have shown the contribution of higher order thinking enhancing techniques in promoting the EFL learners' power of reasoning and the role that private speech has in the process of L2 acquisition.

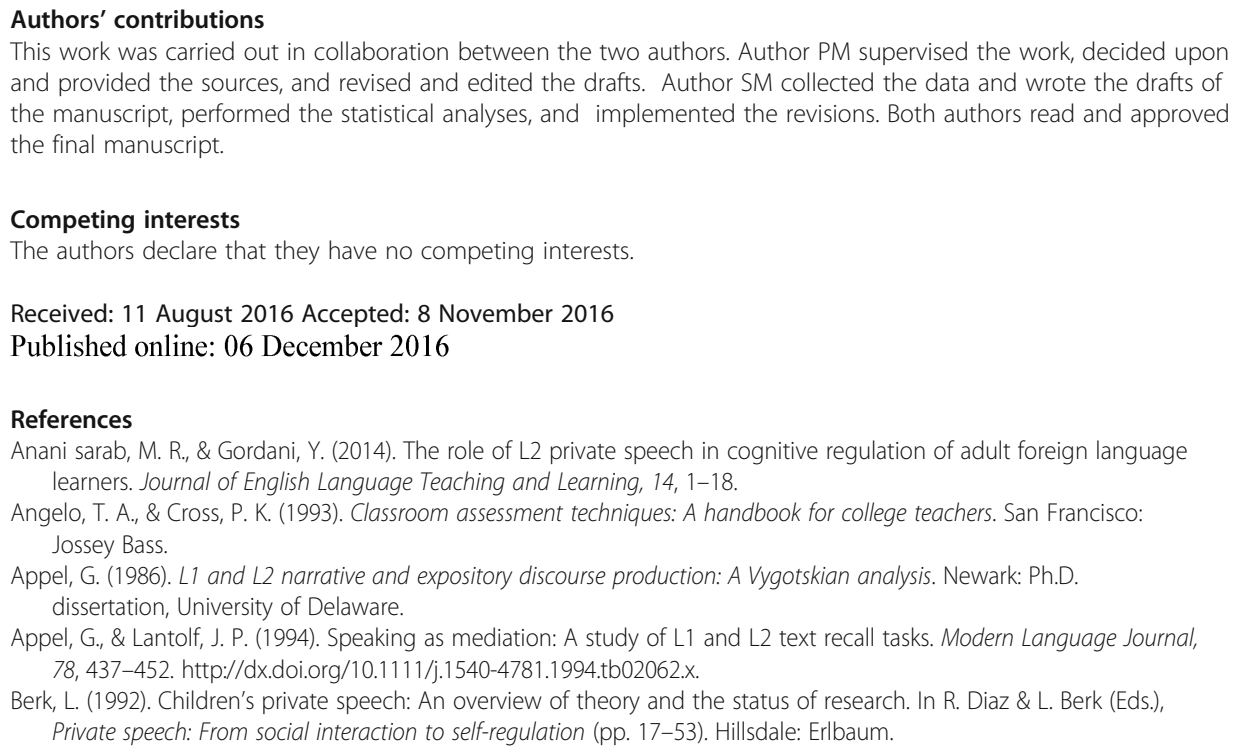


Bivens, J. A., \& Berk, L. E. (1990). A longitudinal study of elementary school children's private speech. Merrill Palmer Quarterly, 36(4), 443-463.

Bowell, T., \& Kemp, G. (2005). Critical thinking, a concise guide (2nd ed.). London: Routledge.

Canas, A. J. (2003). A summary of literature pertaining to the use of concept mapping techniques and technologies for education and performance support (The institute for human and machine cognition).

Canas, A. J., Hill, G., Carff, R., \& Suri, N. (2003). Cmap Tools: A knowledge modeling and sharing toolkit, (technical Reportt IHMC CmapTools, 93-01) (Institute for human and machine cognition).

Carrell, P. L., Pharis, B. G., \& Liberto, J. C. (1989). Metacognitive strategy training for ESL reading. TESOL Quarterly, 23(4), 647-76. http://dx.doi.org/10.2307/3587536.

Centeno-Cortes, B., \& Jimenez Jimenez, A. F. (2004). Problem-solving tasks in a foreign language: the importance of the L1 in private verbal thinking. International Journal of Applied Linguistics, 14(1), 7-35. http://dx.doi.org/10.1111/j.14734192.2004.00052.x

Cohen, A. D., \& Upton, T. A. (2006). Strategies in responding to the new TOEFL reading tasks. TOEFL Monograph Series, 33. doi:10.1002/j.2333-8504.2006.tb02012.x.

Corno, L., \& Mandinach, E. (1983). The role of cognitive engagement in classroom learning and motivation. Educational Psychologist, 18, 88-100.

Dabaghi, A., Zabihi, R., \& Rezazadeh, M. (2012). Argumentative and narrative written task performance: Differential effects of critical thinking. International Journal of Research studies in language learning, 1(2), 1-12.

Diaz, R. M., \& Berk, L. E. (Eds.). (1992). Private Speech: From social interaction to self-regulation. Hillsdale: Lawrence Erlbaum Associates.

Diaz, R., Winsler, A., Atencio, D., \& Harbers, K. (1992). Mediation of self-regulation through the use of private speech. International Journal of Cognitive Education and Mediated Learning, 2, 155-167.

Donato, R. (1994). Collective scaffolding in second language learning. In J. P. Lantolf \& G. Appel (Eds.), Vygotskian approaches to second language research (pp. 33-56). Norwood: Ablex.

Duncan, R. M., \& Cheyne, J. A. (2002). Private speech in young adults, task difficulty, self-regulation and a psychological predication. Cognitive Development, 16, 889-906

English, L. D. (1997). Mathematical reasoning: Analogies, metaphors, and images. New York: Routledge.

Feigenbaum, P. (1992). Development of the syntactic and discourse structures of private speech. In R. M. Diaz \& L. E. Berk (Eds.), Private speech: From social interaction to self-regulation (pp. 181-198). Hiisdale: Erlbaum.

Fernyhough, C., \& Lloyd, P. (1999). Lev Vygtosky: Critical assessments. New York: Routledge.

Frauenglass, M., \& Diaz, R. (1985). Self-regulatory functions of children's private speech: a critical analysis of recent challenges to Vygotsky's theory. Developmental Psychology, 21, 357-364.

Frawley, W. (1997). Vygotsky and cognitive science: Language and the unification of the social and computational mind. Cambridge: Harvard University Press.

Frawley, W., \& Lantolf, J. P. (1985). Second language discourse: a vygotskyan perspective. Applied Linguistics, 6, 19-44. http://dx.doi.org/10.1093/applin/6.1.19.

Freeley, A. J., \& Steinberg, D. L. (2000). Argumentation and debate: Critical thinking for reasoned decision-making. Stamford: Wadsworth.

Ghanizadeh, A. (2007). On the impact of concept mapping on EFL learners' reading comprehension. A paper presented at the fourth conference on issues in language teaching in Iran, Tehran University.

Ghanizadeh, A., \& Mirzaee, S. (2012). Critical thinking: How to enhance it in language classes. Germany: Lambert Academic Publishing.

Green, A. (1998). Verbal protocol analysis in language testing research. Cambridge: CUP.

Hatch, E., \& Lazaraton, A. (1991). The research manual: Design and statistics for applied linguistics. Boston: Heinle \& Heinle Publishers.

Hillocks, G. (2010). Teaching argument for critical thinking and writing: An introduction. English Journal, 99(6), 24-32.

Jonassen, D. H., Carr, C., \& Yueh, H. P. (1998). Computers as Mindtools for engaging learners in critical thinking. Tech Trends, 43(2), 24-32

Kelly, G. J., \& Bazerman, C. (2003). How students argue scientific claims: A rheorical-semantic analysis. Applied Linguistics, 24(1), 28-55.

Khodadady, E., \& Ghanizadrh, A. (2010). The impact of concept mapping on EFL learners' critical thinking ability. English Language Teaching, 4(4), 49-60. 105532/elt.v4n4p49.

Lantolf, J. P., \& Frawley, W. (1984). Second language performance and Vygotskyan psycholinguistics: Implications for L2 instruction. In A. Manning, P. Martin, \& K. McCalla (Eds.), The tenth LACUS forum (pp. 425-440). Columbia: Hornbeam Press.

McCafferty, S. G. (1992). The use of private speech by adult second language learners: a cross- cultural study. Modern Language Journal, 76, 179-89. http://dx.doi.org/10.1111/j.1540-4781.1992.tb01098.x.

McCafferty, S. G. (1994). The use of private speech by adult ESL learners at different levels of proficiency. In J. P. Lantolf \& G. Appel (Eds.), Vygotskian approaches to second language research (pp. 135-56). Norwood: Ablex.

Munro, J. K. (2009). Oral language learning: The primary years (Lecture notes).

Ohta, A. S. (2001). Second language acquisition process in the classroom. Mahwah: Lawrence Erlbaum.

Peters, A. P. (2008). Kinds of thinking, styles of reasoning. In M. Mason (Ed.), Critical thinking and learning. Oxford: Blackwell Publishing.

Pintrich, P. R., \& De Groot, E. V. (1990). Motivational and self-regulated learning components of a classroom academic performance. Journal of Educational Psychology, 82(1), 33-40.

Richmond, K. (2009). Inside Reading 4. Oxford: Oxford University Press.

Salmon, A. K. (2008). Promoting a culture of thinking in the young child. Early Childhood Education Journal, 35, 457-461.

Saville-Troike, M. (1988). Private speech: evidence for second language learning strategies during the 'silent' period. Journal of Child Language, 15, 567-90. http://dx.doi.org/10.1017/S0305000900012575.

Schafersman, S. D. (1991). An introduction to critical thinking. Retrieved from http://www.freeinquiry.com/criticalthinking. html 
Smith, H. J. (2007). The social and private worlds of speech: speech for inter- and intramental activity. The Modern Language Journal, 91, 341-356.

Sonmez, S. S. (2011). A study of private speech and cognitive regulation in native non-native speaker interactions (Ph.D dissertation, The Florida State University, The United States). Retrieved from http://www.diginole.lib.fsu.edu.

Stanley, F. (2011). Vygotsky-from public to private: Learning from personal speech in T. Waller, J. Whitmarsh, \& K. Clarke (Eds.), Making sense of theory and practice in early childhood (pp. 11-25). England: Open University Press.

Talebinezhad, M. R., \& Negari, G. M. (2007). The effect of explicit teaching of concept mapping in expository writing on EFL students' self-regulation. The Linguistics Journal, 2(1), 69-90.

Ushakova, T. N. (1994). Inner speech and second language acquisition: An experimental-theoretical approach. In J. P. Lantolf \& G. Appel (Eds.), Vygotskian approaches to second language research (pp. 135-56). Norwood: Ablex.

Vygotsky, L. S. (1978). Mind in society: The development of higher psychological processes. Cambridge: Harvard University Press.

Vygotsky, L. S. (1986). Thought and language. Cambridge: MIT Press.

Watson, G. B., \& Glaser, E. M. (2002). Watson-Glaser critical thinking appraisal. London: The Psychological Corporation. Watson, G. B., \& Glaser, E. M. (2010). Watson-Glaser critical thinking appraisal: Technical manual and users' guide. The United States of America: Pearson Education.

Wheeler, L., \& Collins, S. (2003). The influence of concept mapping on critical thinking skills in baccalaureate nursing students. Journal of professional Nursing, 19(6), 339-346.

Winsler, A., Abar, B., Feder, M. A., Schunn, C. D., \& Alarcon Rubio, D. (2007). Private speech and executive functioning among high-functioning children with autistic spectrum disorders. Journal of Autism \& Developmental Disorders, 37, $1617-1635$.

Wright, I. (2002). Is that right? Critical thinking and the social world of the young learner. Toronto: Pippin Publishing

Submit your manuscript to a SpringerOpen ${ }^{\circ}$ journal and benefit from:

- Convenient online submission

- Rigorous peer review

- Immediate publication on acceptance

- Open access: articles freely available online

- High visibility within the field

- Retaining the copyright to your article

Submit your next manuscript at $>$ springeropen.com 